\title{
Temperature Stimulation of Effective Value of Density of the Current of Semiconductor Solar Cells
}

\author{
Aliev Rayimjon ${ }^{1}$, Ikromov Rustamjon Gulomjonovich ${ }^{2}$, Alinazarova Mahfuza Alisherovna ${ }^{3}$ \\ ${ }^{1}$ Department of Physics, Andizhan State University, Andizhan, Uzbekistan \\ ${ }^{2}$ Department of Physics, Namangan Engineering and Technology Institute, Namangan, Uzbekistan \\ ${ }^{3}$ Department of Physics, Namangan State University, Namangan, Uzbekistan \\ Email: alievuz@yahoo.com
}

How to cite this paper: Rayimjon, A., Gulomjonovich, I.R. and Alisherovna, A.M. (2019) Temperature Stimulation of Effective Value of Density of the Current of Semiconductor Solar Cells. Energy and Power Engineering, 11, 92-97.

https://doi.org/10.4236/epe.2019.112006

Received: October 23, 2018

Accepted: February 24, 2019

Published: February 27, 2019

Copyright $\odot 2019$ by author(s) and Scientific Research Publishing Inc. This work is licensed under the Creative Commons Attribution International License (CC BY 4.0).

http://creativecommons.org/licenses/by/4.0/

\begin{abstract}
Influence of temperature on effective value of a current density of a semiconductor solar cell is investigated. New equations for explanation of dependence of photovoltaic characteristics of solar cell from temperature are received.

\section{Keywords}

Semiconductor Solar Cell, Effective Value of a Current, Temperature

Dependence of Photovoltaic Parameters, Photovoltaic Characteristics
\end{abstract}

\section{Introduction}

The semiconductor photo-electric power takes a perspective place among set of renewable energy. Thus on a way of wide application of solar cells (SC) in power supply programs, there are some problems. Most considerable of them are the high cost price of solar energy and low efficiency of SC [1].

Semiconductor SC with high cost can be used without an exception in various special conditions. For example, at their use as an energy source of space flying devices, they are exposed to essential cooling [2]. At use of SC for conversation of the concentrated radiation is inevitable their strong heating [3]. Therefore, research of temperature properties of SC is one of important applied problems of a modern science.

Now is spent theoretical and experimental researches influence of ambient temperature on the cores Photovoltaic parameters of SC [2]. For interpretation of the temperature properties of SC defined experimentally scientists often address to the received by theoretical way laws. Thus quite often there are inex- 
plicable known theoretical expressions, temperature dependences, the cores of Photovoltaic parameters of SC. Such situation demands necessity of working out of more suitable semi-empirical expressions for the description of experimental dependences. The given work is devoted this problem-to definition of semi-empirical expressions for more exact definition of temperature properties of semiconductor SC with $p$ - $n$-structure.

\section{Methodology}

Influence of ambient temperature and, hence, the most SC on its photovoltaic characteristics and efficiency of photoelectric conversation by semiconductor structures is the most important object of experimental and theoretical research. It is known that one of the basic photovoltaic characteristics of SC, defining efficiency of conversation of solar energy is effective power which is traditionally expressed by formula [1]:

$$
P_{m}=j_{m} U_{m}
$$

where $J_{m}$ and $U_{m}$ are maximum (effective) values of according to photocurrent density and voltage.

Experimental results show that $J_{m}$ and $U_{m}$ are depends on temperature. But in the scientific literature the expressions allowing preliminary to define these dependence almost are not presented.

Therefore in this work the results, the research conducted by us by a semi-empiric method definition of dependence of effective value of $J_{m}$ and $U_{m}$ from temperature are stated.

On Figure 1 the qualitative method of definition of a point of effective power, from experimental I - V (3-curve) of SC is shown. For this purpose in the beginning define a straight line passing through two points of I - V, voltage of idling and density of a current of short circuit, i.e. ( $U_{o c}$ whence are defined; 0$)$ and (0; $J_{s c}$ (1-straight line). By parallel shifting of this line to a effective point of SC I - V it is possible to receive a 2-straight line. From this I - V point defines effective power of SC. Being based on this method it is possible to deduce the formula for defining effective value of density of a photo current of SC developed.

As it is known the equation for a straight line which is passing through two points has the following appearance

$$
\frac{j-j_{1}}{j_{2}-j_{1}}=\frac{U-U_{1}}{U_{2}-U_{1}}
$$

From this Equation (2) it is possible to receive for a 1-straight line (Figure 1):

$$
j=-\frac{j_{s c}}{U_{o c}} U+j_{s c}
$$

It is visible that the angular factor of this straight line matters $a=-\frac{j_{s c}}{U_{o c}}$. For a 2-straight line also looks like $j=a U+b$. As, the 2-straight line is a tangent to $\mathrm{I}-\mathrm{V}$, therefore angular factor of this line it is possible to define from I - V: 


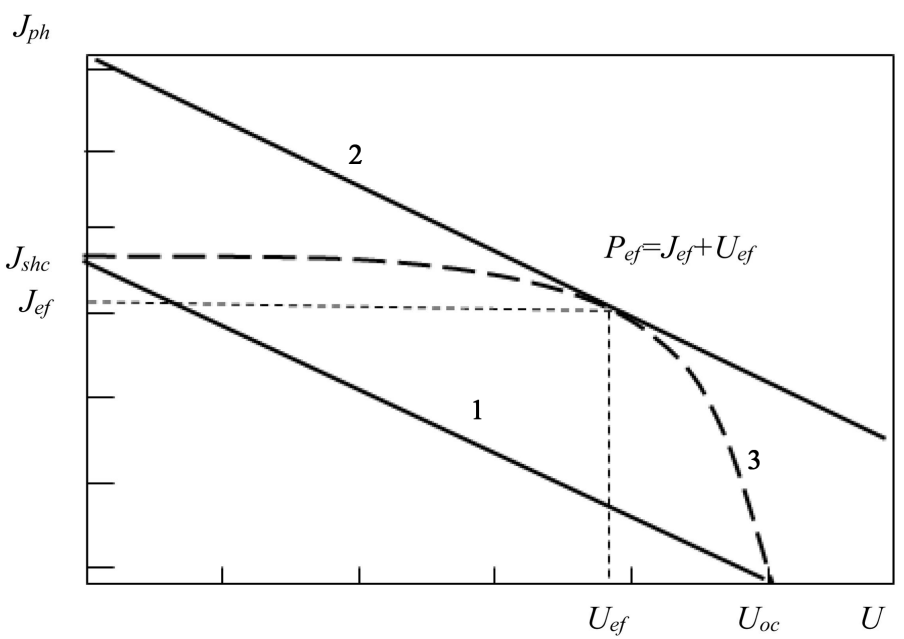

Figure 1. A method of definition of a point of effective power from experimental I - V of SC.

$$
j_{p h}=j_{0}\left(\exp \left(\frac{e U}{n k T}\right)-1\right)-j_{s c}
$$

where $j_{p h}$-photocurrent density, $j_{0}$-density of a saturation current, $e-$ a electron charge, $k$-constant of Boltzmann, $T$-temperature.

It is known that value of factor not idealities $(n)$ of SC I - V is define by type of an electric current [4]. Therefore, it is possible to assume that leaving voltage of SC does not depend on this parameter. We define a derivative on pressure from SC I - V and we will find its value at $U=U_{m}$ then for and we will receive:

$$
a=j_{p h}^{\prime}\left(U_{m}\right)=-j_{0} \frac{e}{n k T} \exp \left(\frac{e U_{m}}{n k T}\right)
$$

From a condition of parallelism of two straight lines, the angular factor of these lines should be identical:

$$
\frac{j_{s c}}{U_{o c}}=j_{0} \frac{e}{n k T} \exp \left(\frac{e U_{m}}{n k T}\right)
$$

From equality (6) for effective value of SC voltage $\left(U_{m}\right)$ we will receive:

$$
U_{m}=\frac{n k T}{e} \ln \left(\frac{j_{s c}}{j_{0}} \frac{n k T}{e U_{o c}}\right)
$$

Substituting the expression, defining effective value of SC voltage $\left(U_{m}\right)$, we receive for effective value of density of a current:

$$
\begin{gathered}
j_{m}=j_{0}\left(\exp \left(\frac{e U_{m}}{n k T}\right)-1\right)-j_{s c} \\
j_{m}=j_{s c}\left(\frac{n k T}{e U_{o c}}-1-\frac{j_{0}}{j_{s c}}\right)
\end{gathered}
$$

As it is known, both $j_{0}$ saturation, and $j_{s c}$ short circuits, and $U_{o c}$-voltage of idling depend on temperature [5] [6]: 


$$
\begin{aligned}
& j_{0}=j_{00} \exp \left(-\frac{e \varphi}{k}\left(\frac{1}{T_{0}}-\frac{1}{T}\right)\right) \\
& j_{s c}=j_{00} \exp \left[\frac{e \varphi}{k}\left(\frac{1}{T_{0}}-\frac{1}{T}\right)\right]\left[\exp \left[\frac{e \varphi}{n k T_{0}}\left(\frac{U_{0 o c}}{\varphi}-1+\frac{T_{0}}{T}\right)\right]-1\right] \\
& U_{o c}=\left(U_{0 o c}-\varphi\right) \frac{T}{T_{0}}+\varphi
\end{aligned}
$$

where $U_{o o c}-$ open circuit voltage at room temperature. As shown in work [7] of I - V ideality factor does not depend on temperature in the range of $100<\mathrm{T}<500$ K.

On the other hand, dependence of height of a potential barrier $\varphi$ from temperature of SC at not so low temperatures can be described in a kind:

$$
\varphi=\varphi_{0}-\gamma T
$$

where $\varphi_{0}$-height of a potential barrier at temperature $\mathrm{T}=0, \gamma$-temperature factor of height of the potential barrier, having identical sense with temperature factor of width of the band gap [5]. Value $\varphi_{0}$ can be defined, from the formula (11), by extrapolating dependence of voltage of idling on temperature $U_{o c}(T)$ to $T=0 \mathrm{~K}$. From a temperature dependence of width of the band gap knows that value of temperature factor of height of a potential barrier lies in an interval $10^{-3}$ $\div 10^{-5} \mathrm{~V} / \mathrm{K}[8]$.

\section{Results \& Discussion}

On Figure 2 results of experiment (curve-1) and calculation (curve-2) the currents of short circuit for SC which made on the base of $A l G a A s$-GaAs [1] received by (11) temperature dependence are presented. Conformity of results of experiment and calculation (section $\mathrm{A}$ ) is received for dates: $n=1.0028 ; \varphi_{o}=$ $1.42 \mathrm{~V}$ and $\gamma=5 \times 10^{-5} \mathrm{~V} / \mathrm{K}$. From drawing, it is visible that expression (11) not only explains results of experiences but also supplements them (Section A and C). Calculations have shown that short circuit currents of these SC at $T=500 \mathrm{~K}$ have a weak maximum $\left(J_{s c} \approx 122 \mathrm{~mA}\right)$, at temperatures more low $T=120 \mathrm{~K}$ and above $T=620 \mathrm{~K}$ start to decrease strongly. It is defined also that short circuit currents at temperatures $T<110 \mathrm{~K}$ and $T>770 \mathrm{~K}$ will be equal to zero $\left(J_{s c}=0\right)$. These results once again show correctness of the expressions received in works [5] [6].

Now we pass to calculation of temperature dependence of effective value of SC current density. Delivering expressions for currents density of $j_{o}$-saturation and $J_{s h c}$-short circuit, and $U_{o c}$-voltage of idling in (9) is possible to receive the formula defining temperature dependence of effective value of density of SC current.

On Figure 3 results of experiment (curve-1) and calculation (curve-2), received by this formula for SC on the base of $A l G a A s-G a A s$ [2] are resulted. Conformity of these results (Section $\mathrm{B}$ ) are received at values $n=2.5 ; \varphi_{o}=1.42 \mathrm{~V}$ 


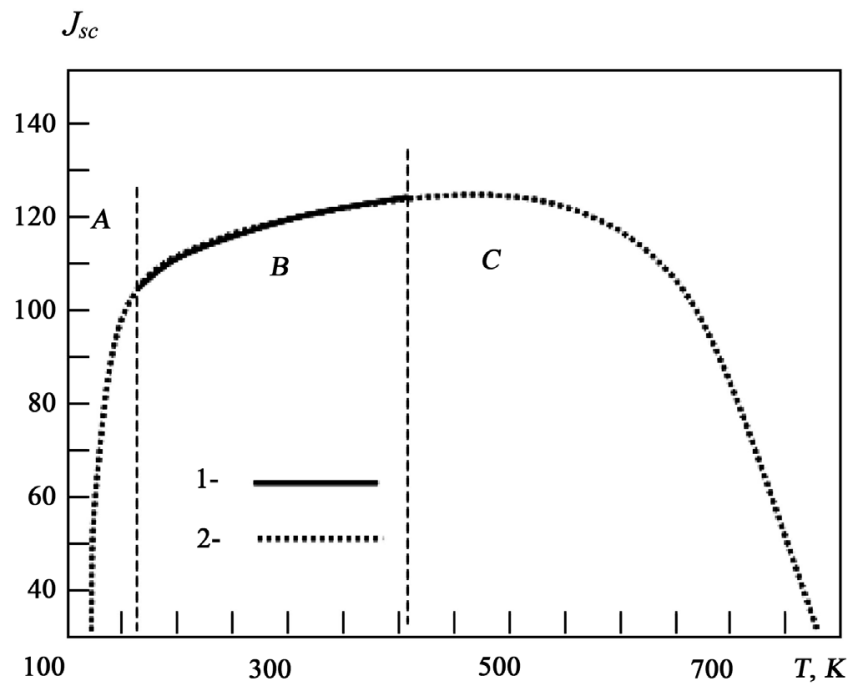

Figure 2. Dependence of density of a current of short circuit $(\mathrm{mA})$ on temperature SC. 1-experiment [2] and 2-results of calculation from expression (11) when $\mathrm{n}=1.0028 ; \varphi_{\mathrm{o}}=$ $1.42 \mathrm{~V}$ and $\gamma=5 \times 10^{-5} \mathrm{~V} / \mathrm{K}$.

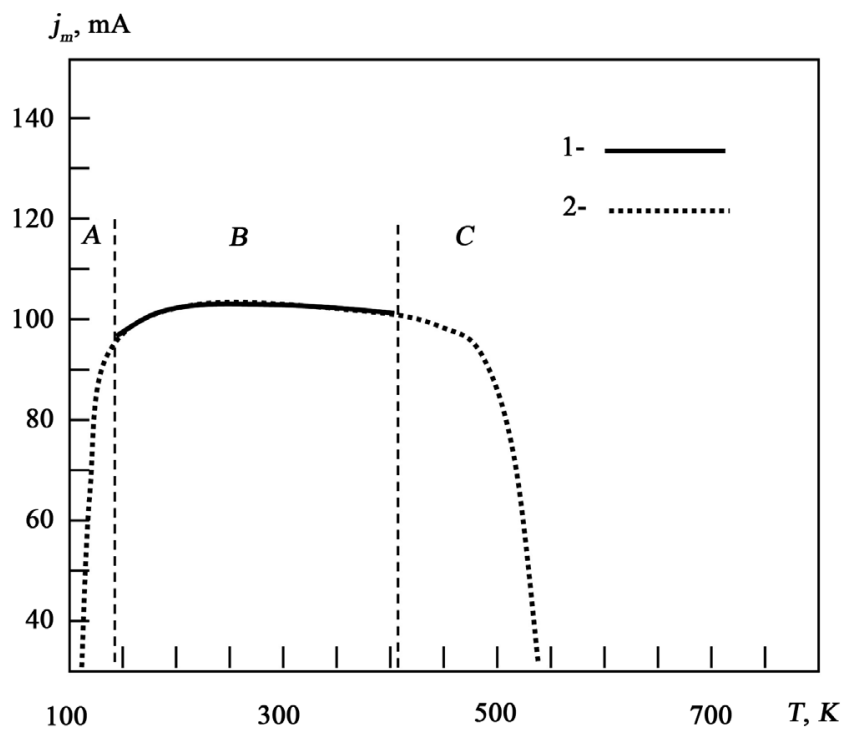

Figure 3. Dependence of effective value of SC current density on temperature. 1-experiment [2] and 2-results of calculation received by expression (9) at $\mathrm{n}=2.5 ; \varphi_{\mathrm{o}}=$ $1.42 \mathrm{~V}$ and $\gamma=2 \times 10^{-4} \mathrm{~V} / \mathrm{K}$.

and $\gamma=5 \times 10^{-5} \mathrm{~V} / \mathrm{K}$. It is visible that in the expressions received for temperature dependence of short circuit current density and of current effective value from temperature has distinction only in values of I - V not ideality factor (n) of SC. This says that electric current type in these points of I - V differs from each other. From drawing it is visible that, as well as the density, and a short circuit current, and effective value of current density of SC have a weak maximum at $T$ $=200 \mathrm{~K}\left(J_{m} \approx 119 \mathrm{~mA}\right)$. Value of this photovoltaic characteristic in temperatures more low $T=120 \mathrm{~K}$ (Section A) and above $T=470 \mathrm{~K}$ (Section C) begin will strongly decrease. Calculations also have shown that at $T<110 \mathrm{~K}$ and $T>540 \mathrm{~K}$ 
value of effective density of a current equals to zero $\left(J_{m}=0\right)$.

\section{Conclusions}

In the scientific point of view, influence of temperature on effective value of current density of a semiconductor SC is investigated. The new expression allowing more approximately explain of experimental dependence of SC photovoltaic characteristics from temperature is received. We will notice that the new formulas received in this work for definition of dependence of the basic photo-galvanic characteristics of solar cells from temperature can use for SC on any semiconductor material basis.

From the practical point of view, it is established that SC, made on semiconductor alloy $A l G a A s-G a A s$, is not expedient to use at temperatures lower $T=$ $110 \mathrm{~K}$ and above $T=540 \mathrm{~K}$ (that follows because of equality to zero of effective value of current density of such SC).

\section{Conflicts of Interest}

The authors declare no conflicts of interest regarding the publication of this paper.

\section{References}

[1] Natarova, J.V., Gnatenko, A.S. and Galat, A.B. (2018) Research of Photo-Electric Converters on the Basis of Various Semiconductor Materials. Journal of Nano- and Electronic Physics, 10, 04023. (In Russian)

[2] Bjub, F.A. (1987) Solar Cells (the Theory and Experiment). M, Energoatomizdat, 278 p. (In Russian)

[3] Bavin, M.R. (2014) Development and Research of Refracting Photoelectric Installations. The Dissertation on Competition of a Scientific Degree of Cand. Tech. Sci. a Speciality 05.14.08, Power Installations on the Basis of Renewable Energy. Moscow, 139 p. (In Russian)

[4] Zi, S. (1984) Physics of Semiconductor Devices. The Book 1, M, Mir, 456 p. (In Russian)

[5] Zaynobiddinov, S., Ikramov, R.G., Aliev, R., Ismanova, O.T., Niyazov, O. and Nuritdinova, M.A. (2003) Influence of Temperature on Photoelectric Characteristics of Solar Cells from Amorphous Silicon. Geliotecknica, №3, 19-22. (In Russian)

[6] Aliev, R., Zaynobiddinov, C., Ikramov, R.G., Ismanova, O.T. and Nuritdinova, M.A. (2003) An Estimation of Photoelectric Parameters of Solar Cells on the Basis of Amorphous Silicon. Geliotecknica, № 1, 18-22. (In Russian)

[7] Aliev, R., Alinazarova, M.A., Ikramov, R.G. and Ismanova, O.T. (2009) Features of Influence of Temperature on Photocurrent of Solar Cell, Created on the Basis of the Amorphous Semiconductor. Geliotecknica, № 3, 15-20. (In Russian)

[8] Aut, I., Gentsov, D. and Herman, T. (1980) The Photoelectric Phenomena. M, Mir, 208 p. (In Russian) 